\title{
POLÍTICAS SOBRE A VIDA E A REIVINDICAÇÃO PELO USO MEDICINAL DA MACONHA
}

\section{POLICIES ON LIFE AND CLAIM BY MEDICAL USE OF MARIJUANA}

\author{
Natália de Campos \\ natalia262@gmail.com \\ Bacharel em Ciencias Sociais (UFRN), Mestre e Doutora em Antropologia Social pelo Programa de Pós- \\ Graduação em Antropologia Social da Universidade Federal do Rio Grande do Norte (PPGAS/UFRN), \\ Professora da Universidade Estadual da Paraíba. \\ Orcid: https://orcid.org/0000-0001-5928-4798
}

\section{RESUMO}

Este artigo busca, a partir das discussões de Michel Foucault e Didier Fassin, apontar as relações entre as políticas de Estado sobre a vida dos indivíduos e as estratégias acionadas pela população para ter acesso ao direito à saúde. Entre os casos que tratam desta temática já explorada por outros autores das ciências sociais e especialmente da antropologia, inserimos nesta discussão uma demanda bastante específica e atual, sobre o uso de derivados da maconha para fins medicinais, terapêutica utilizada há alguns anos em outros países e recentemente discutida no Brasil com consideráveis limitações e entraves. Assim, apresentamos as formas como a sociedade articula-se e aciona dispositivos do próprio Estado para obter reconhecimento dos seus direitos e acesso para as suas demandas por saúde.

Palavras-chave: Saúde. Estado. Maconha medicinal.

\begin{abstract}
This paper seeks, based on Michel Foucault and Didier Fassin's discussions, to point out the relations of State policies on life of the individuals and their strategies as a population to put in action their access to healthcare rights. Although this topic has been discussed by other authors in social sciences, anthropology above all, this paper inserts a very specific and current demand in these discussion, the use of medical marijuana derivatives for medicinal purposes, therapy that has been used for a couple of years in other countries and recently discussed in Brazil although with considerable limitations and obstacles. Thus, we point out how society articulates itself activating the State's own devices to obtain recognition of its rights and access to society demands for healthcare.
\end{abstract}

Keywords: Healthcare. State policies. Medical marijuana.

As questões que envolvem Justiça e direitos relacionados à casos de saúde e doença e, consequentemente, a demandas específicas por cidadania, podem ser entendidas, entre diversas abordagens, pelo seu contexto de ordem 
política, que desvela as formas de interferência do Estado e suas normas sobre questões de ordem individual específicas.

É o caso da recente demanda pelo uso da maconha para fins terapêuticos no Brasil, considerando seu potencial efeito na diminuição de sintomas de diversas doenças graves, debilitantes e incuráveis. A descoberta deste tratamento em outros países chega ao Brasil cercada por questões de cunho burocrático, moral e de justiça, que podem ser compreendidos a partir de discussões em desenvolvimento há décadas nas ciências sociais, como veremos, sobretudo a partir de Foucault e suas interpretações das formas de ação do Estado sobre a vida dos indivíduos.

\section{BIOPODER E REGULAÇÃO SOCIAL NA VIDA INDIVIDUAL}

Foucault, em diversos escritos, toma como foco central para suas análises o poder, suas formas e sentidos na vida social. Partindo do entendimento sobre o poder instituído nas formas do Estado, em "Direito de Morte e Poder Sobre a Vida", Foucault retoma o poder Soberano para explicar as mudanças e diferenças deste em relação às formas de governo posteriores, instituídas a partir do final do Século XVII. O autor explica que o poder Soberano, caracterizado pelo "direito de apreensão das coisas, do tempo, dos corpos e, finalmente, da vida" (FOUCAULT, 1977, p. 146), culminava na possibilidade de exterminá-la, já que aquele que detinha o poder tinha o direito legítimo de dispor direta ou indiretamente sobre a vida dos seus súditos, "causar a morte ou deixar viver". Em casos de guerra, por exemplo, o soberano exporia indiretamente seus súditos à morte, em batalhas em defesa do Estado. Por outro lado, infringir as leis ou atentar contra o Soberano dá a este o direito de ordenar diretamente ao transgressor sua condenação à morte como forma de castigo.

Porém, a partir da época clássica, os mecanismos de poder sofreram transformações importantes. Causar a morte deixa de ser a forma principal de manutenção do poder e o controle e gestão da vida ganham espaço no ordenamento social como forma de poder. Nas palavras de Foucault, "a velha potência da morte em que se simbolizava o poder soberano é agora, cuidadosamente, recoberta pela administração dos corpos e pela gestão calculista da vida" (FOUCAULT, 1977, p. 150). Pretende-se, a partir de então, o poder sobre a vida "causar a vida ou devolver à morte", marcado pelas formas de gestão dos corpos e das sociedades. Por um lado, "o corpo como máquina" passa a ser regulado e adequado a fins, adestrado, ampliando suas aptidões e extorquindo suas forças, tornando-o útil e dócil, alguns dos meios de integrar os indivíduos à sistemas de controle e aproveitamento econômico. Por outro lado, "o corpo-espécie" passa a focar as sociedades em seus processos biológicos de proliferação, nascimento e morte, longevidade, saúde e variadas formas de intervenção e controle reguladores da vida, o que Foucault chamou de uma biopolítica da população. Caracteriza-se assim o que o autor conceituou como biopoder, marcado pelas disciplinas do corpo ("corpo como máquina") e as regulações da população (“corpo-espécie").

Se o desenvolvimento rápido das diversas formas de disciplina durante a época clássica marca a era do Biopoder, é a partir do século XIX que os agenciamentos concretos passam a configurar uma tecnologia política da vida como forma de controle sobre os corpos e as populações. Instituições como as escolas e o Exército são exemplos das disciplinas aplicadas aos indivíduos para condicioná-los aos sistemas econômicos úteis ao Estado. Igualmente, a atenção dedicada à estatística voltada para dados da população e as técnicas políticas 
de controle sobre natalidade, longevidade, saúde, habitação, etc., são condições descritas por Foucault como essenciais para o desenvolvimento do capitalismo. Além das disciplinas e das formas de controle das populações, o autor observa a importância das normas e leis jurídicas, reguladoras e corretivas, como meios de garantir a adequação dos indivíduos às normas.

Não é à toa que Foucault aponta a sexualidade como um dos principais focos de atenção e disputa política, já que as duas formas de cerceamento e controle passam por questões sexuais, tanto no que tange às disciplinas do corpo, quanto à regulação das populações. Para ele, "o sexo é acesso, ao mesmo tempo, à vida do corpo e à vida da espécie. Servimo-nos dele como matriz das disciplinas e como princípio das regulações" (FOUCAULT, p. 158). Por consequência, a regulação dos corpos e das populações desencadeia, entre outros aspectos, o desenvolvimento das formas de controle e cuidado da saúde como princípio de manutenção da vida, sobretudo nas cidades, onde o aglomerado populacional é responsável pelo alastramento de doenças.

Em "O nascimento do Hospital" (FOUCAULT, 1979), apresenta as mudanças hospitalares, desde sua fundação - voltada para abrigar e cuidar dos moribundos às vésperas da morte - até sua medicalização quando, de fato, os hospitais passam a ser espaços terapêuticos, de cuidado e atenção aos doentes, no final do século XVIII, tomando de exemplo os hospitais militares e marítimos onde soldados deveriam ser recuperados para voltarem aos combates e demais tarefas, sem serem desperdiçadas vidas treinadas. Mesmo nos espaços hospitalares, o autor destaca a fundamental importância das disciplinas para ordenar, separar, restringir, classificar os doentes de acordo com sua enfermidade, os espaços físicos de acordo suas funções, os profissionais em hierarquia de importância e responsabilidades, e as terapias por sua forma de aplicação, controle, acompanhamento e eficácia. Para ele, "é a introdução dos mecanismos disciplinares no espaço confuso do hospital que vai possibilitar sua medicalização" (FOUCAULT, 1979, p. 182), e mais, é através do conjunto de técnicas disciplinares que será possível ter como objetivo os indivíduos em sua singularidade.

O espaço hospitalar, para Foucault, apresenta ainda outra dimensão, também disciplinar e de controle, que perpassa e transcende sua proposta de cura, no que diz respeito à formação normativa dos médicos a partir da experiência e conhecimento da prática clínica

\footnotetext{
Clínica aqui significa a organização do hospital como lugar de formação e transmissão de saber. Mas se vê também que, com a disciplinarização do espaço hospitalar que permite curar, como também registrar, formar e acumular saber, a medicina se dá como objeto de observação um imenso domínio, limitado, por um lado, pelo indivíduo e, de outro, pela população. Pela disciplinarização do espaço médico, pelo fato de se poder isolar cada indivíduo, colocá-lo em um leito, prescrever-lhe um regime etc., pretende-se chegar a uma medicina individualizante. Efetivamente, é o indivíduo que será observado, seguido, conhecido e curado. O indivíduo emerge como objeto do saber e da prática médicos. [...] O indivíduo e a população são dados simultaneamente como objetos de saber e alvos de intervenção da medicina, graças à tecnologia hospitalar (FOUCAULT, 1979, p. 188-189).
}

No trecho acima, fica clara a integração entre as formas de controle exercidas pelo biopoder na gestão da vida, individual e coletiva. É no aprendizado, mas também nas práticas, que o biopoder e a biopolítica se entremeiam e se concretizam no corpo dos indivíduos através das instituições, como o ambiente hospitalar tão bem representa. 
Há ainda outra dimensão política que precisa ser relacionada às já citadas formas de controle sobre as populações, e trata-se do entendimento que Foucault elabora sobre o papel e a importância da população para a gestão governamental. Sobretudo como estratégia de governo, como fim e instrumento, a população passa a ser entendida como riqueza central de uma nação. É para ela e por ela que o governante deve governar, mas é também através dela que alcançará bons resultados para a economia política, sendo esta a forma de governar que percebe que, através de técnicas e tecnologias, voltadas para a população, consegue exercer o poder e gerir o Estado. As colocações de Foucault sobre as formas de poder e sua íntima relação com as formas de governo na gestão de um Estado, relações estas bastante presentes nas sociedades modernas, nos fazem entender os meios pelos quais a vida dos indivíduos está não apenas atrelada à vida social, como diretamente também em relação com as políticas e formas de governo. Não há individualidade que não esteja contabilizada nas estatísticas e estimativas, ou que não seja alvo de formas de controle.

A vida privada, e até mesmo o sexo e a sexualidade, como Foucault chama atenção, são alvo direto dos Governos e da gestão do Estado. Exemplos práticos, como a criminalização do aborto, deixam claro o quanto cada indivíduo é regido e regulado por formas de controle e, em último grau, por penalidades em caso de infração ou desvio às normas. Para garantir o poder do Estado sobre sua população, são as vidas e os processos vitais que estão sob gestão e controle e, nesse sentido, questões que envolvam a manutenção dos corpos fazem parte deste domínio de regulação. A saúde e a doença, em particular, são regidas não apenas por preceitos da medicina ocidental, atualmente considerada superior e quase absoluta em relação às demais formas de cuidado, mas também por uma série de normatizações, permissões e proibições de práticas e terapias permitidas de acordo com leis específicas em cada país. Para o uso medicinal da maconha, singularmente no Brasil, podemos perceber a presença dessa gestão institucional da medicina e do Estado sobre o corpo, a doença e as possíveis terapias autorizadas para sanar ou amenizar dores e sintomas sentidos individual e coletivamente por pacientes e seus familiares em razão de doenças incuráveis e de difícil controle.

O uso medicinal da maconha no Brasil é um exemplo das formas como o biopoder age sobre a vida dos indivíduos, por um lado limitando seu acesso à saúde (nos termos de fazer viver e deixar morrer) e, por outro, criminalizando práticas que poderiam garantir melhor qualidade de vida a uma parcela da sua população. Isso porque, apesar de criminalizado no Brasil, o uso da maconha para fins terapêuticos é comprovado, reconhecido e prescrito para tratamentos de saúde em outros países como Espanha, Canadá, Itália, Estados Unidos, Reino Unido, Israel e Holanda. Pesquisas estrangeiras atestam o uso de alguns dos princípios ativos da Cannabis como eficazes remédios no tratamento de doenças incuráveis, como a epilepsia, para as quais os remédios à base de maconha proporcionam drástica redução nos sintomas e sofrimento dos portadores (CARLINI; ORLANDI-MATTOS, 2011).

Até pouco tempo, este uso medicinal não era possível no Brasil e pacientes ou familiares que buscassem os medicamentos de forma ilegal em países estrangeiros estavam suscetíveis a serem enquadrados como traficantes por praticarem ato criminoso de transporte de substâncias ilegais, independente da finalidade, condição que levou estas famílias a cogitarem mudar de país para terem acesso ao tratamento com derivados da maconha. Ao invés disso, famílias e grupos de pacientes cujos medicamentos à base de maconha são recomendados para o tratamento das suas doenças, entraram com processos judiciais solicitando ao Estado Brasileiro que fosse permitida a importação desses medicamentos e sua retirada da lista de sustâncias ilícitas classificadas 
pela ANVISA, com base nas comprovações estrangeiras pois, criminalizada, a maconha não pode ser estudada por pesquisadores no país e sua importação se torna uma operação demorada e de alto custo, condições que impedem que os tratamentos sejam realizados de forma contínua. Visando a ampla utilização desses fármacos no tratamento de variadas doenças para as quais seu uso é recomendado internacionalmente, processos judiciais de diferentes ordens vêm sendo acionados, solicitando a legalização e regulamentação da maconha para fins medicinais no país, estratégia que pouco a pouco tem conquistado aberturas legais para este tratamento.

Atualmente, o Conselho Federal de Medicina recomenda a prescrição médica apenas de um dos princípios ativos da maconha, o canabidiol (CBD) de forma bastante restrita, exclusivamente para o tratamento de crianças com epilepsia de difícil controle, embora a Anvisa permita a importação de extratos de maconha contendo outras substâncias, inclusive o tetra-hidrocanabinol (THC), para uma variedade de doenças, ainda que seja necessário apresentar uma prescrição médica para tal solicitação. A divergência de posicionamentos entre o CFM e a ANVISA coloca os médicos dispostos a acompanhar o tratamento dos seus pacientes com estas substâncias em condição delicada em relação ao seu conselho profissional, motivo pelo qual poucos profissionais assumem este risco e responsabilidade, o que acarreta em mais um entrave para a utilização desta terapêutica.

Vemos assim que, embora haja comprovações científicas e casos clínicos que comprovem a eficácia desse tratamento, não se trata unicamente de uma escolha individual do paciente e seus familiares em optarem por um tratamento específico que lhes proporcione melhor qualidade de vida. Na prática, essa escolha é cerceada por limitações legais, impostas pelo Estado, e pela regulação e restrição imposta aos profissionais da medicina pelo seu conselho federal, o que resulta não em uma escolha e tratamento, mas em uma batalha judicial pelo direito à saúde que vai de encontro aos limites de controle biossocial, ou, como diria Foucault, esbarra no biopoder.

\section{UMA ECONOMIA MORAL PARA A VALORAÇÃO DA VIDA HUMANA E A ATUAÇÃO DO ESTADO}

Fassin, dedicado aos estudos sobre questões de saúde, doença, migração e discriminação, baseia-se no pensamento de Foucault para problematizar de que formas as políticas de saúde são parciais e economicamente tendenciosas, conferindo benefícios e cuidado a parcelas específicas da população. A partir do que Foucault denominou biopoder como poder sobre a vida, como tratamos anteriormente, Fassin reelabora esta definição para falar de poder da vida, que trata do reconhecimento social sobre as questões do corpo sofredor ou doente (FASSIN, 2012). Nesse sentido, não mais biopoder, mas biolegitimidade é o conceito utilizado por Fassin para tratar desta dimensão

Trata-se, com essa palavra, de enunciar uma ordem de valores - e não uma hierarquia de poderes - que existem no mundo contemporâneo e cujas traduções concretas são inumeráveis, tanto nos espaços locais da saúde pública, quanto nas cenas mundiais da ação humanitária (FASSIN, 2012, p. 381).

O exemplo tratado por ele em alguns escritos (FASSIN, 2001, 2012) a respeito da imigração na França esclarece seus argumentos. Recuperando as políticas cada vez mais restritivas quanto à entrada e permanência de estran- 
geiros no país a partir da década de 1970, Fassin aponta uma mobilização ideológica e política que relacionou diretamente a presença de imigrantes como problemática em relação à oferta de empregos, à insegurança e até mesmo a questões de saúde como a Aids, criando representações discriminatórias sobre pessoas de outros países e justificando práticas cada vez mais inospitaleiras para elas. Nesse contexto, o autor destaca dois fenômenos que embasam sua teoria sobre a biolegitimidade. O primeiro fenômeno trata da perda de legitimidade do asilo político a refugiados a partir dos anos 1980, caracterizada pela diminuição considerável do número de concessões à solicitantes, seguida por outras políticas dissuasivas contra candidatos a condição de refugiados, como a perda de auxílio moradia em 1989 e a proibição de trabalhar no país em 1991, tornando-os dependentes de ações humanitárias e da caridade pública. Por outro lado, o segundo fenômeno aponta a razão humanitária como um novo direito, pois, a partir dos anos 1990, estrangeiros com graves problemas de saúde e sem condição de tratamento adequado em seu país de origem tem condição legítima para reconhecimento e aceitação legal para entrada e permanência para tratamento na França.

Perda de legitimidade de asilo político, de um lado; recuperação de legitimidade do corpo em sofrimento, de outro. Dois modos de definir uma política dos viventes. Temos boas razões para estabelecer esse paralelo entre os dois fenômenos porque não apenas eles se desenvolvem durante o mesmo período, mas porque operam de modo interativo. [...] Lidamos, portanto, com um verdadeiro deslocamento de legitimidade: dos direitos do cidadão do mundo (ameaçado em seu país) aos direitos do ser humano (marcado pela doença). [...] Hoje a sociedade francesa está menos inclinada a reconhecer a existência de risco de vida de uma vítima de um regime autoritário ou de violências de guerra, porém mais sensível à doença ou ao sofrimento da pessoa atingida por uma afecção grave (FASSIN, 2012, p. 384).

É neste sentido, reforçando a inclinação valorativa da sociedade francesa em legitimar uma das justificativas para concessão de imigração, em detrimento de outra, que Fassin elabora em termos de uma economia moral sobre as políticas dos vivos, referindo-se a elevada importância dos valores que servem de base para as escolhas feitas pelas sociedades contemporâneas sobre questões relacionadas à existência física, corporal, mas também social dos indivíduos (FASSIN, 2012). Com essa formulação, Fassin faz um contraponto ao que Foucault chamou de Economia Política, tratando das formas e propósitos do biopoder exercido pelo Estado. Isso porque não é mais a força de trabalho e a contribuição econômica que serão consideradas, o corpo doente é que desperta um novo reconhecimento, "a biopolítica da alteridade deve aqui ser entendida como uma redução extrema do social para o biológico: o corpo parece ser o refúgio final de uma humanidade comum" (FASSIN, 2001, p. 5).

Para os fins das suas pesquisas, os desdobramentos desenvolvidos por Fassin apontam que a questão da imigração na França e seus meandros - no que diz respeito à valoração e consequente distinção entre causas patológicas e políticas para aceitação ou não estrangeiros em seu país - são, na verdade, sintomas do preconceito e da discriminação contra povos imigrantes, sobretudo aqueles provenientes da África do Norte e subsaariana, praticada de forma velada e negada pela França (FASSIN, 2001). O autor trata sobre a racialização, mais ampla do que o exemplo francês e que não se restringe a distinguir apenas franceses de não-franceses, mas de europeus e não-europeus. Para Fassin, estas formas de discriminação e classificação social provocam o que ele conceituou como "bio-inequalities" (biodesigualdades), pois quando a desigualdade social é pensada através do corpo, o Estado não somente normatiza ou racializa o corpo, 
mas decide também que tipo de vida as pessoas podem ter, ou ainda, que tipos de direitos eles vão receber (FASSIN, 2009).

Para ele, ainda que nas sociedades contemporâneas a preocupação esteja voltada para o direito de vida, o biopoder também trata sobre morte. Quando políticas sociais de saúde propõem uma qualidade de vida a alguns em detrimento de outros, o poder do Estado opta também por dar menos tempo de vida a parcela menos favorecida.

Também parcialmente amparadas pelos desígnios foucautianos e partindo de pontos de vista semelhante aos de Fassin, os esforços de Das e Pooleem definir as formas de ação do Estado e suas margens, se mostram como uma visão interessante sobre como o Estado intervém na vida social e os limites que ele estabelece, mas aos quais também está condicionado. As autoras citam diversos contextos em que a atuação do Estado se dá de forma parcial, imprecisa ou mesmo é inexistente em função dos seus limites de intervenção social, territorial e legal. Das e Poole, através de situações diversas, conseguem definir algumas questões substanciais para problematizar esta relação entre Estado e sociedade, sobretudo através das suas funções ordenadoras, limitações, incongruências e a marginalização de determinados segmentos sociais.

Como primeiro ponto comentado por Das e Poole que nos interessa recuperar, trata do uso legítimo da força pelo Estado, através dos poderes militares, para garantir a ordem social, manter a vigilância e, quando necessário, intervir no descumprimento da lei. Das e Poole recorrem aos escritos de Weber para conceituarem que,

\begin{abstract}
Una organización gobernante será considerada política en tanto y en cuanto su existencia y orden sobre un territorio esté continuamente salvaguardada por la amenaza y la aplicación de la fuerza física por parte de su personal administrativo. Una organización política obligatoria con operaciones continuas será llamada estado en tanto y en cuanto su aparato administrativo mantenga para sí, con éxito, el monopolio del uso legítimo de la fuerza en la aplicación del orden por él estabelecido (WEBER, 1978, p. 54 apud DAS; POOLE, 2008, p. 22)
\end{abstract}

O monopólio do uso da força pelo Estado, ou por outros tipos de organização quando prescrito por ele, é para Weber tão essencial na constituição do Estado quanto sua natureza de jurisdição obrigatória e constante. De fato, a legitimidade do uso da força se dá enquanto braço ativo da ordem jurídica para a vigilância e o cumprimento das leis na ordem do cotidiano social. Para as autoras, essa questão é primordial pois o controle sobre o cumprimento da lei e da ordem social estabelece os limites entre o que deve ser considerado como parte do Estado e o que deve ser excluído dele. Isso vale para o uso da força em contextos de guerra, mas também no uso da violência policial.

Esta forma de intervenção governamental é problemática se considerarmos, no caso do Brasil, por exemplo, que as forças policiais, uma das instâncias mais expressivas da administração pública, age direta e principalmente em periferias de forma violenta e direcionada aos segmentos sociais desfavorecidos, vitimando milhares de pessoas por ano e ainda assim é considerada legítima pelos órgãos da Justiça.

No entanto, como comentado por Fassin, há o fator moral presente na forma e no direcionamento da força que permite que o abuso desta ferramenta seja tolerado e até mesmo positivado pelas instâncias jurídicas do Estado. Nesse sentido, Das e Poole entendem que "los hombres cuyas habilidades para representar al estado, o hacer cumplir sus leyes, están basadas en el reconocimiento de la impunidad de los mismos para moverse entre la apelación a la ley y las 
prácticas extrajudiciales" (DAS; POOLE, 2008, p. 29), o que os coloca em posição privilegiada diante das normas estabelecidas.

O entendimento de Fassin sobre o que ele denominou biolegitimidade e bio-desigualdades nos remete a questões sobre o uso da maconha que possibilitam um entendimento específico sobre as vidas envolvidas. Se entrecruzarmos discussões sobre uso medicinal/terapêutico e uso recreativo da maconha, perceberemos uma discrepância de entendimentos e aceitação social entre esses usos, quase como se estivéssemos tratando de substâncias ou espécies vegetais distintas e não é à toa que muitas vezes o debate sobre maconha medicinal seja feito com o nome cientifico da planta, Cannabis, e não maconha, que denota uma distinção de interpretação como se não fossem exatamente a mesma coisa, o que repercute também em quem faz uso desta planta, sobretudo para usuários medicinais que adquirem legitimidade em sua reivindicação, ao contrário de usuários recreativos da mesma planta, que serão alvo de diversos julgamentos morais estigmatizantes.

Ainda nesta tentativa de distinção e de segmentação social dos usos e usuários de cada "tipo", a partir das pesquisas que estamos desenvolvendo, percebemos que a organização de associações e grupos de pacientes e seus familiares que realizam a mobilização pelo uso terapêutico da maconha pode ser caracterizado por pessoas com nível elevado de educação e economicamente estruturadas, que as coloca em condição privilegiada para investirem tempo neste tipo de organização para além do tempo necessário de dedicação aos cuidados com a saúde dos pacientes em tratamento. Essas distinções permitem, por exemplo, que algumas famílias, moradoras de bairros e regiões urbanas de classe média/alta, consigam autorização judicial para cultivarem pés de maconha e extraírem artesanalmente em suas próprias casas os derivados necessários para as terapias individuais de seus familiares, geralmente crianças, sem qualquer importunação policial ou acionamento judicial decorrente desta prática. Embora tal possiblidade seja o ideal para muitas famílias, não é difícil perceber que nem sempre isso será possível, em razão das distinções de conhecimentos jurídicos sobre direitos, locais de moradia, rede familiar de apoio e inviabilidade financeira, entre outros fatores que se colocam como questões para pensarmos sobre quais são os critérios e possibilidades para o uso medicinal da maconha em um cenário moral que impõe cuidados e prerrogativas para aqueles que entendem o acesso à saúde como direito fundamental que merece ser conquistado e assegurado, mas que se caracteriza, ainda, como biodesigualdade, ou seja, limitado à uma parcela favorecida da população brasileira. Ao mesmo tempo, estas questões evidenciam ainda sobre quem, ou sobre quais parcelas da população as forças do Estado são impostas, como discutem Das e Poole.

\section{NORMAS LEGAIS, PRECEITOS MORAIS}

Outro sentido atribuído por Das e Poole à proposta de estabelecer as margens do Estado, diz respeito as formas de poder exercidas sobre os corpos, assim como conceituou Foucault sobre o poder disciplinar e biopoder e seus mecanismos de controle sobre os indivíduos e a sociedade. Para as autoras, a concepção de margens reside entre os corpos, as leis e a disciplina, pois o poder soberano do Estado não é efetivado apenas sobre territórios e esferas coletivas, mas está sendo concretizado nas formas de controle médicas que estabelecem padrões de normalidade em oposição a quesitos patologizantes. Além do exemplo sobre o aborto, citado anteriormente, o uso de substâncias psicoativas ilícitas também se configura como uma forma de controle que nos fornece a dimensão precisa entre normalidade/anormalidade, legalidade/ilegalidade, pois, entre tantas substâncias lícitas, seja de uso médico (fármacos), 
alimentar (açúcar, cafeína) ou lúdico (álcool, tabaco) amplamente aceitas socialmente e utilizadas em larga escala, que provocam alterações metabólicas e tem poder viciante, as condenadas pela lei como ilegais (maconha, cocaína, LSD, etc.) são alvo de condenação legal e moral (CAMPOS, 2013), sem considerar seus possíveis usos benéficos.

Assim como nas questões envolvendo o uso da força de forma legítima unicamente pelo Estado, nas formas de controle exercidas sobre o corpo é latente a dimensão moral presente nestas estratégias de intervenção do Estado, através de políticas governamentais, que refletem padrões normatizados da vida social. A conceituação de Foucault sobre as formas de controle individuais e coletivas, como já foi colocado, se efetivam nas normas sociais acatadas massivamente pela sociedade em forma de valores e práticas.

A ordem jurídica e legal é um dos pilares cruciais que estabelece estas normas sociais, demarcando os preceitos básicos de determinada cultura a partir de um conjunto burocrático de regras reunidas sob forma de lei. Porém as normas estabelecidas burocraticamente pela administração pública não têm sua aplicação restrita aos poderes legais. É importante perceber que elas passam a ter status de verdades absolutas que, reafirmadas socialmente, constituem a contínua manutenção social da normatividade estabelecida. Por um lado, se "as regras do direito delimitam formalmente o poder, por outro, os efeitos de verdade que este poder produz, transmite e que por sua vez reproduzem-no. Um triângulo, portanto: poder, direito e verdade" (FOUCAULT, 1979, p. 278). Nos termos foucaultianos, esta é mais uma condição estabelecida pela biopolítica que se reproduz em diferentes direções. Há que se ter a dimensão que a instituição governamental impõe à sociedade, suas postulações desdobram-se em valores morais socialmente compartilhados que definem populações, grupos sociais, práticas ou posicionamentos específicos em termos de sua adequação ou não à normatividade.

Aqui, mais uma vez, como fazem as ciências sociais ao longo da sua existência, remontamos as construções sociais na forma como todos os aspectos da vida em sociedade são culturalmente construídos, desde suas instituições mais rígidas até as concepções que pensamos ser universais ou individuais, da noção de Estado aos valores morais. Sequer a vida, em si mesma, tem valor natural ou igual entre diferentes indivíduos. E quanto ao valor da vida, não me refiro ao seu valor entre diferentes espécies - o que também é fato. Mesmo a vida humana tem diferentes valores perante a lei e a sociedade a depender de quem é o indivíduo. Seu valor estará condicionado ao seu papel e inserção social, e isso diz muito sobre a moralidade presente em determinada sociedade. Entre os indianos, por exemplo, as diferentes castas atribuem valor aos Brâmanes, enquanto subjugam os Dalit, baseados em valores religiosos que, embora não sejam mais determinados em termos legais, implicam diferentes valorações morais reais e concretas naquela sociedade.

Em termos da administração pública e de políticas governamentais, as distinções valorativas se dão em outros termos. A biopolítica que serve para gerir a vida social no sentido de prover as condições necessárias à vida normatizada daqueles que estão socialmente integrados e que, por isso suas vidas são valoradas, é também formada por mecanismos de abandono aos que são julgados como sem valor e que, portanto, "se dejan morir" (DAS; POOLE, 2008, p. 40). Não é difícil perceber essa dupla valoração.

Ainda assim, é necessário perceber que a economia moral relacionada à valores sociais, de que trata Fassin, - assim como a biopolítica e o biopoder de Foucault - não é unilateral, bem como não está restrita unicamente nas formas institucionalizadas do Estado e nas suas políticas. Igualmente, as 
biopolíticas desenvolvidas como forma de controle não são aceitas com tanta docilidade e parcimônia. Há resistência e divergências quanto às formas de poder institucionalizadas, bem como há subversão às normas e formas de driblar as técnicas e seus objetivos. Fassin diz que os indivíduos não são passivos neste processo, eles desenvolvem táticas para burlar ou adequar as exigências do país aos seus propósitos, pelo princípio de que "os fins justificam os meios". Ora, se é permitido a um estrangeiro entrar na França legalmente caso apresente uma comprovação de doença sem tratamento no seu país de origem, é provável que ele se adeque à exigência em troca do visto de permanência que lhe dará melhores condições de vida, transformando sua vida biológica em uma passagem necessária que o possibilitará uma vida política mais digna. Assim, Fassin observa que "as vidas concretas escapam, em parte, à normatização" (FASSIN 2012, p. 385).

Há outros desdobramentos do que foi abordado por Foucault e Fassin que envolvem questões de saúde diretamente relacionadas com as biopolíticas, porém com direcionamentos e contextos específicos. É o caso do acidente nuclear de Chernobyl ocorrido em 1986, analisado por Petryna em "Life Politics after Chernobyl" (2002). A pesquisadora relata o que conseguiu colher em 18 meses de pesquisa de campo com vítimas do acidente e documentação sobre o evento a respeito do impacto social e biológico provocados pelo desastre. Após a catástrofe, a omissão do governo soviético ao não reconhecer as consequências do desastre implicou em sequelas e danos ainda piores para a população e para o meio ambiente. Na tentativa de diminuir o número de pessoas assistidas, sintomas e doenças que apareceram posteriormente ao acidente foram desconsideradas e, por essa razão, até os dias atuais não existe uma quantificação precisa do número de pessoas afetadas pelo desastre e o número de mortes decorrentes dele. Fica claro no texto a falta de assistência à população na época do acidente, mas também posterior a ele. Petryna destaca as manobras governamentais para negar direitos aos afetados e dá atenção especial aos percursos e estratégias elaboradas pelas vítimas para garantirem direitos e assistência governamental.

Articuladas em termos de cidadania biológica, a reivindicação por amparo do Estado foi elaborada a partir de categorias biomédicas, classificando os afetados em termos dos efeitos que sofreram e que podiam comprovadamente serem relacionados a radioatividade do desastre. Entre categorias como "deficientes" e "sofredores", parte dos afetados foram desconsiderados como merecedores de assistência pelo Estado, mas, do ponto de vista das vítimas, seria melhor ser classificados como deficientes à ficarem sem direitos, sobretudo no contexto histórico e político da época, em que o regime soviético havia declinado e a recente Ucrânia era um país pobre marcado pela escassez de trabalho. Aceitar e reivindicar a classificação de deficiente, foi a alternativa acionada pela população afetada pelo desastre nuclear para garantir direitos.

Aqui, fica clara a discordância entre as biopolíticas elaboradas pelo Estado para conter e tentar mascarar os graves efeitos do desastre de Chernobyl, em oposição às reivindicações sociais daqueles que foram diretamente atingidos pela radiação de várias formas. A reivindicação de uma biossocialidade, amparada por conceitos e classificações biomédicas permitiram as vítimas obter legitimidade em sua demanda, conquistando direitos imprevistos pelo Estado. $\mathrm{O}$ caso investigado por Petryna representa aquilo sobre o que falava Michel Foucault e Didier Fassin sobre a imprevisibilidade da vida concreta em relação às normas instituídas.

Biehl e Petryna (2011), em trabalho conjunto, abordam outro tema interessante para pensar as políticas de Estado sobre a vida dos indivíduos. Trata-se da judicialização da saúde, pesquisada por eles a partir do caso de pais que entram com ações litigiosas contra o Estado Brasileiro pelo acesso 
aos medicamentos de alto custo que seus filhos, portadores de mucopolissacaridose, necessitam para tratamento contínuo por toda a vida. No Brasil o litígio por acesso à saúde, sobretudo à medicamentos, é uma rota alternativa de acesso à um direito social previsto na Constituição Federal. Embora o país tenha um sistema público de saúde, o SUS, ele não é eficaz e não consegue arcar com toda a complexidade dos casos de saúde. Os autores apontam as diversas instâncias de governo, sobretudo estaduais e municipais, como responsáveis pelos problemas de má gestão que, por consequência, não conseguem suprir as necessidades de saúde da população, nem mesmo fornecer os tratamentos e medicamentos que, de acordo com a lei, deveriam estar disponíveis. Por outro lado, o sistema de saúde privado, embora pretenda fornecer um serviço melhor, não inclui medicamentos.

Biehl e Petryna situam que as demandas judiciais por acesso à saúde começaram pelo esforço de ativistas da Aids por acesso aos medicamentos antirretrovirais. Até 1998 os requerentes exigiam quase exclusivamente os medicamentos para tratamento do HIV/Aids, porém, a partir do ano seguinte houve uma diversificação dos tipos de tratamentos e patologias que entraram em litígio por direito à saúde. Além da diversificação, a quantidade de requerimentos também aumentou significativamente de 4 casos em 1995, para $314 \mathrm{em}$ 1997 e chegou a 1.144 em 2002, apenas no estado do Rio de Janeiro (BIEHL; PETRYNA 2011).

Os casos estudados por eles referem-se a um novo limiar do direito à saúde, isso porque o tratamento para mucopolissacaridose diz respeito às terapias genéticas que, por serem oriundas de tecnologias de ponta e fazerem parte de um mercado altamente rentável, tem custos bastante elevados e não fazem parte da lista de medicamentos disponibilizados pelo Sistema Único de Saúde. Somados ao alto custo, a burocracia do sistema jurídico brasileiro não permite que uma decisão judicial favorecendo os pacientes seja suficiente para garantir o tratamento reivindicado. Ao contrário, cada decisão, individual para cada paciente, tem validade determinada, o que obriga os pais das crianças a sempre retornarem ao sistema judicial com um novo pedido de tratamento que nem sempre é julgado e concedido antes de interromper o tratamento conquistado anteriormente, descontinuando as terapias e prejudicando a melhora e a saúde dos pacientes.

Problematizando este caso a partir dos conceitos de Foucault, percebe-se a precariedade das intervenções biopolíticas da saúde pública brasileira em tentar suprir, sem sucesso, as demandas sociais, cedendo aos interesses de um mercado farmacêutico que negocia com o governo o alto custo para acesso ao que os autores chamam de biotecnologia, necessária para tratamentos raros ou recentemente descobertos.

É o caso também das demandas pelo uso terapêutico da maconha que, em razão da falta de regulamentação nacional, esta suscetível a judicialização para que pacientes tenham acesso aos derivados terapêuticos e, no caso de importação, muitas vezes há também a necessidade de reivindicar que o Estado seja obrigado a garantir o fornecimento, arcando com os altos custos dos produtos e das taxas de importação e, ainda assim a morosidade jurídica e de cumprimento das sentenças por parte do Estado muitas vezes interrompem o tratamento dos pacientes. Percebemos então que, embora a norma esteja posta, existem formas de questioná-la.

Assim também ocorre com o estudo etnográfico realizado por Nguyen (2010) no contexto da epidemia de HIV/Aids no oeste africano, a respeito da "promessa de tratamento" e mobilização coletiva por acesso à medicamentos anti-HIV. Este autor apresenta a organização de uma militância terapêutica 
que desafia as imposições internacionais e desenvolve suas próprias estratégias para conseguir tratamento, pressionando politicamente instituições biomédicas pela cura; engajada no processo de pesquisas laboratoriais, disponibilizando-se, inclusive, para experimentar as novas drogas; desenvolvendo a expertise entre os ativistas sobre o campo biomédico; estimulando o engajamento político dos seus participantes; e organizando um grupos de ajuda mútua em torno da doença.

Estas estratégias e a inserção dos ativistas nas diversas frentes de reivindicação por tratamento, configuram o que Nguyen (2010) chama de cidadania terapêutica que, neste contexto, tem papel fundamental para a conquista do tratamento para o maior número de pessoas do grupo. O que o autor ressalta são os processos internos de disputa pelo tratamento entre os próprios membros do grupo, quais deles receberão tratamento primeiro, já que não está disponível para todos? Uma questão delicada, já que aqueles que não recebem imediatamente as medicações têm maiores chances de não sobreviverem. Assim, a triagem nasce em um campo de batalhas: recursos escassos para o tratamento e a necessidade de manter aqueles que são mais ativos na luta pelos demais, em detrimento dos que terão que esperar, sem saber se sobreviverão. A estratégia desenvolvida pelo grupo surpreende ao empregar uma forma de escolha que beneficia indiretamente o maior número de pessoas. Por isso são escolhidos aqueles que melhor sabem contar sua história e detém a habilidade de "capitalizar redes sociais" para representar o grupo e conseguir apoio e maior quantidade de medicamentos para o tratamento dos demais, a fim de tratar mais pessoas, numa espécie de cálculo social - aquele que receber o medicamento, precisa transpor esse bem aos outros.

Nesse sentido, a organização do grupo em redes de solidariedade, comunidades de pessoas com HIV, diferencia as pessoas que receberiam tratamento (e viveriam) das que não receberiam, o que poderia gerar a aflição dos que precisam esperar e o sentimento de desigualdade. No entanto, a formação destas redes, a interação entre os doentes, as narrativas das experiências com o HIV, testemunhos e confissões, aproximaram as pessoas e diminuíram a competitividade, produzindo a afirmação de uma cidadania terapêutica.

Da mesma forma, as famílias que se unem em associações para reivindicar o direito à terapias com derivados da maconha, também podem ser categorizadas pela militância terapêutica descrita por Nguyen (2010), em busca de cidadania terapêutica e como forma de apoio mútuo nas dificuldades e diferentes situações que permeiam os cuidados e as formas de acesso à maconha terapêutica em várias partes do Brasil. As mesmas estratégias e ações caracterizam estes grupos que, para ter acesso ao tratamento, fazem pressão política e divulgação social do tema, buscam aliados de diversas áreas científicas, reivindicando pesquisas nacionais que deem aporte científico para a regulamentação do uso medicinal da maconha, aprofundam a expertise entre as famílias e se ajudam mutuamente, em redes de solidariedade reais e virtuais de compartilhamento de angustias, saberes, conquistas e avanços.

\section{PROVOCAÇÕES PARA AMPLIAÇÃO DO DEBATE}

Os casos que ilustram esta discussão perpassam os conceitos e teorias que tratam das formas de poder do Estado, mas também das estratégias individuais e coletivas acionada por populações para burlar ou adequar suas demandas as normas, ou para converter as normas às suas demandas. Ainda assim, a questão que interliga estes estudos diz respeito ao valor dado à vida de diferentes povos 
e segmentos sociais. Quais vidas contam, quais vidas valem? Quem merece acesso a tratamento e a direitos? Aqui retomo aquilo que foi explanado anteriormente a respeito das proposições de Fassin sobre as discriminações e os valores desiguais atribuídos a diferentes povos. Porém, faz sentido neste caso também, aquilo que foi afirmado sobre o papel do ativismo e da militância para obtenção de direitos e sua importância no emaranhado de relações de poder para encontrar as formas de acesso ao Estado por meios não previstos nas biopolíticas. Didier Fassin tratou profundamente sobre estes temas e é interessante perceber que sua visão sobre a necessidade de encontrar formas de acesso às políticas sobre a vida se torna a única forma de garantir a sobrevivência daqueles que são desprezados pelas políticas de Estado e até pelas instituições internacionais. Lutar pela vida, nesse sentido, significa considerar que "a ameaça que pesa sobre a vida física se torna sua razão para viver” (FASSIN, 2012, p. 384).

Entender o Estado nas suas ramificações de poder a partir desta complexa rede de influências, implica percebê-lo, através da administração pública, como dotado de moralidades e valores expostos e reproduzidos socialmente. Para tanto, é necessário entender que, por administração pública devemos considerar além das suas esferas governamentais - municipal, estadual e federal —, sua morfologia, operações cotidianas — nas práticas estruturantes e estruturadas pela história institucional e pela interação de seus funcionários - e seus aspectos normativos (VIANNA, 2013, p. 18). Este amplo entendimento sobre as ramificações do Estado na sociedade através das instâncias da administração pública e seus agentes, nos permite perceber a infinidade de definições normativas a que uma sociedade está condicionada e com as quais opera, não apenas em termos legais, mas sobretudo de forma prática entre os indivíduos: "las personas representan la ley, la burocracia y la violencia, son las que juntas constituyen el movimiento del estado por detrás del reino de lo mítico, para unirse en la realidad de la vida cotidiana" (DAS; POOLE, 2008, p. 30).

Se estas autoras buscaram definir o Estado em termos do que o constitui e das suas margens enquanto aquilo que foge ou deforma sua concepção, vale considerarmos que os aspectos estruturais sob os quais elas constroem sua argumentação não são apenas legais, mas operam sobretudo dentro do território social e político em que de fato se dão.

As proposições conceituais dos autores aqui recuperados nos fornecem moldes para tentarmos traçar contornos teóricos que facilitam a compreensão desta estrutura abstrata que é o Estado, porém, nos interessa sobretudo sua operacionalização real, que se estabelece através de políticas governamentais efetivadas no cotidiano social. Nesse sentido, é a administração pública que consolida, através da implementação de políticas, os preceitos estruturais que configuram o Estado em sua relação com a sociedade. Logo, devemos perceber “o papel da administração pública enquanto nexo articulador/normatizador/ codificador entre costumes heterogêneos, constituindo [inclusive] moralidades" (SOUZA LIMA, 2002, p. 16) e, por consequência, a forma como estas questões estão intrinsecamente relacionadas.

Dada a interface entre o direito individual à saúde e as disposições reguladoras do Estado, pensar o uso medicinal da maconha no Brasil atualmente, como vemos, extrapola questões de saúde por ser ainda mais amplo, já que envolve uma diversidade de atores e instituições, articuladas entre si, que atuam nas possibilidades ou não de mudar concepções morais e legais que condenam a maconha por ser considerada droga. O preconceito socialmente compartilhado foi um dos principais entraves iniciais encontrados na reivindicação do uso medicinal da planta, mesmo com as comprovações cientificas que atestam sua eficácia. Já o papel regulador do Estado, nesse caso, aparece na forma do controle moral instituído por um preconceito engessado em forma 
de tabu sobre o uso de substâncias que, a princípio, são categorizadas como drogas e estão condenadas ao ilícito. Por consequência, os sujeitos envolvidos na questão também são criminalizados. O que poderia ser a solução para casos de saúde específicos, enfrenta barreiras concretas em termos legais e morais apenas por surgir na contramão do que se instituiu como verdade sobre o tema.

Esta questão tem avançado no Brasil, porém sua definitiva mudança de status da ilegalidade para a legalidade ainda tem um longo percurso jurídico e moral a enfrentar. A Lei de Drogas (Lei 11.343/2006), embora preveja a possibilidade de pesquisas e usos médicos para as substâncias nela enquadradas, exige uma regulação para estas aplicações que só começou a ser realizada a partir de 2015. Mesmo antes disso, as famílias que precisam desta medicação até então ilícita, burlavam a legislação e importavam ilegalmente os extratos de maconha livremente comercializados em outros países, para o tratamento de crianças portadoras de doenças caracterizadas por epilepsia refratária aos medicamentos disponíveis no mercado nacional — um problema que não pode esperar pelos passos lentos da burocracia jurídica.

Uma sociedade com seus pré-conceitos, arraigados em padrões morais, não dá atenção aos problemas sociais que permeiam as nossas cidades e a dinâmica da vida, sobretudo urbana, reafirmando formas de sofrimento, exclusão e violência. Para além das distinções socialmente compartilhadas, há ainda interesses econômicos e políticos em jogo. Populações envolvidas em conflitos sociais ou que reivindicam mudanças por aquilo que acreditam e por melhorias para suas necessidades, muitas vezes organizam-se e manifestam-se de formas variadas para serem ouvidas pelos poderes públicos e pela sociedade mais ampla, como tem acontecido no caso do movimento pelo direito ao uso medicinal da maconha.

O fato é muitas das questões que se configuram como problemas sociais, não são de interesse dos poderes públicos no país, algumas até são esquecidas propositalmente em nome de interesses escusos ou tratadas de forma pontual com direcionamentos específicos e parciais, que não resolvem e mantém estas populações em situação de sofrimento social, como tratam Pusseti e Brazzabeni (2011):

O poder que se procura analisar, todavia, não entra em jogo somente para produzir as condições que favorecem a exclusão social, mas também para criar respostas institucionais e políticas de intervenção adequadas ao sofrimento que se propõe aplacar. Seguindo a proposta de Fassin $(2005,2006)$, um dos maiores desafios atuais consiste em investigar as políticas contemporâneas, não tanto nas suas instituições e técnicas, quanto no ethos que as anima e que Fassin (2005) define como "ethos da compaixão": trata-se de políticas que se empenham em aliviar o sofrimento, afastando o olhar das suas próprias causas.

Sofrimento social é, de facto, um conceito muito utilizado hoje, não somente nas ciências sociais, mas também nos programas governamentais e não governamentais de apoio social, e que abrange aspetos diferentes relacionados com a perda de qualidade de vida, podendo ser vivenciado tanto no plano individual quanto no plano coletivo (PUSSETI; BRAZZABENI, 2011, p. 472).

No caso da maconha medicinal, foi necessário que a sociedade civil, organizada em associações de pacientes, acionasse o Estado através de mecanismos jurídicos para que o sofrimento social, individual e coletivo, ao qual pacientes e seus familiares estavam submetidos, fosse sanado através da regulamentação de importação e uso, permitindo o acesso ao tratamento com derivados da Cannabis $\mathrm{e}$, consequentemente, melhor qualidade de vida para os envolvidos. 
Assim como os casos descritos, as estratégias de importação ilegal e reivindicação jurídica por acesso aos derivados da maconha para uso medicinal constituem aquilo que Fassin apontou sobre a imprevisibilidade da vida concreta, que escapa as normas instituídas.

Considerando a atualidade desta demanda por saúde, imprevista pelas políticas do Estado que pretendem controlar a vida dos indivíduos, como vimos em Foucault e Fassin, fica claro que as formas de gestão políticas possibilitam que os indivíduos encontrem formas de burlar e transgredir leis, e exijam aquilo que lhes é de direito, mas não está acessível, por vias do próprio Estado.

A judicialização da saúde em um país que preconiza o acesso a ela de forma universal e irrestrita, porém não a fornece, é um exemplo do que Fassin escreveu sobre vidas concretas ou, como diria Foucault, "foi a vida, muito mais do que o direito, que se tornou o objeto das lutas políticas, ainda que estas últimas se formulem através de afirmações de direito" (FOUCAULT, 1979, p. 157). E se for essa a via de acesso possível, que assim seja, até que se possa efetuar mudanças concretas que permitam que a saúde seja um direito realizado. Para os tratamentos com maconha, parece que ainda caminhamos devagar até a concretização deste direito e as estratégias possíveis ainda são transgredir as leis e judicializar o acesso.

Já as nossas análises sobre este caso transpassam teorias e conceitos que, embora formulados para questões distintas, de outras épocas e regiões do globo, se mostram apropriadas para entendermos de que formas o Estado está presente na vida individual, cerceando e moldando a vida muito mais do que um olhar apressado poderia desvelar. Percebemos assim, como as forças institucionais muitas vezes se opõem as necessidades individuais, ao mesmo tempo que as pessoas, dentro das suas possibilidades, agem e reagem de acordo com os imperativos da vida cotidiana.

\section{REFERÊNCIAS BIBLIOGRÁFICAS}

BIEHL, João G.; PETRYNA, Adriana. "Bodies of right and therapeutic markets". Social Research, v. 78, n. 2, p. 359-386, 2011.

BRASIL. Lei $n^{\circ} 11.343$, de 23 de agosto de 2006. Institui o sistema nacional de políticas públicas sobre drogas - SISNAD; prescreve medidas para prevenção do uso indevido, atenção e reinserção social de usuários e dependentes de drogas; estabelece normas para repressão à produção não autorizada e ao tráfico ilícito de drogas; define crimes e dá outras providências. Diário Oficial da União, Brasília (DF). Disponível em: https://www.planalto.gov.br/ ccivil_03/_Ato2004-2006/2006/Lei/L11343.htm. Acesso em: 15 maio 2020.

CAMPOS, Natália de. Militância, Organização e mobilização antiproíbicionista da maconha: coletivos, eventos e marchas em Natal (RN). Dissertação de Mestrado - PPGAS/UFRN. 2013.

CARLINI, Elisaldo Luis de Araújo; ORLANDI-MATTOS, Paulo Eduardo. Cannabis sativa 1 (maconha): medicamento que renasce? Brasília: Revista Brasília Med, v. 48, n. 4, p. 409-415, 2011.

DAS, Veena; POOLE, Deborah. El estado y sus márgenes: etnografias comparadas. Cuadernos de antropología social, n. 27, p. 19-52, 2008.

FASSIN, Didier. The biopolitics of otherness". Anthropology Today, 2001.

. "Another politics of life is possible". Theory, Culture and Society, v. 26,

n. 5, 2009. 
. "O sentido da saúde: antropologia das políticas da vida". In: SAILLANT, Francine; GENEST, Serge (orgs.). Antropologia médica: ancoragens locais, desafios globais. Rio de Janeiro: Editora Fiocruz, 2012.

FOUCAULT, Michel. "O direito de morte e poder sobre a vida". In: História da Sexualidade. Rio de Janeiro: Graal, 1977.

. "O nascimento do hospital"; "A governamentalidade". In: Microfisica do poder. Rio de Janeiro: Graal, 1979.

NGUYEN, "Life itself: triage and therapeutic citizenship". In: The Republic of Therapy. Triage and sovereignity in West Africa's time of AIDS. Durham: Duke University Press, 2010.

PETRYNA, Adriana. "Life Politics after Chernobyl". In: Life Exposed, biological citizens after Chernobyl. Princeton: Princeton University Press, 2002.

PUSSETTI, Chiara; BRAZZABENI, Micol. Sofrimento social: idiomas da exclusão e políticas do assistencialismo. Etnográfica. Revista do Centro em Rede de Investigação em Antropologia, v. 15, n. 3, p. 467-478, 2011.

SOUZA LIMA, Antonio C. de. "Sobre gestar e gerir a desigualdade: pontos de investigação e diálogo". In: Gestar e gerir. Estudos para uma antropologia da administração pública no Brasil. Rio de Janeiro: Relume Dumará, 2002.

VIANNA, Adriana. "Apresentação"; "Introdução: fazendo e desfazendo inquietudes no mundo dos direitos". In: O fazer e o desfazer dos direitos: experiências etnográficas sobre política, administração e moralidades. Rio de Janeiro: Laced/E-papers, 2013. 